\title{
Reflections
}

\section{Mapping the 'gray area' - commentary to Tulumello}

\author{
JOUNI HÄKLI
}

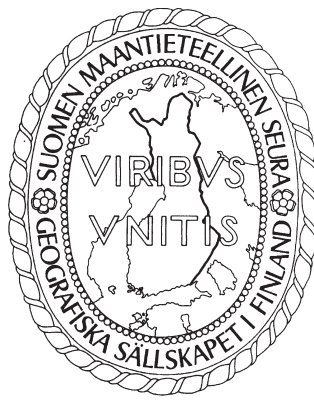

Häkli, J. (2019) Mapping the 'gray area' - commentary to Tulumello. Fennia 197(1) 158-159. https://doi.org/10.11143/fennia.80011

As a response to Simone Tulumello's essay ‘Generalization, epistemology and concrete: what can social sciences learn from the common sense of engineers', in this commentary I reflect on some of the issues that I consider key elements in his provocative original text. I mainly pay attention to the question of balancing between ideal-typical simplification and nuance in Tulumello's argumentation, pointing at the risks involved in a writing strategy that seeks not only to engage and inspire but also persuade and convince.

Keywords: methodology, generalization, reflexivity, subjectivity

Jouni Häkli, Space and political Agency Research Group (SPARG), Faculty of Management and Business, Tampere University, Finland. E-mail: jouni. hakli@tuni.fi

Simone Tulumello's (2019) paper is an essay that addresses some major methodological issues in social research in an engaging and somewhat provoking manner, and indeed playfully. Proposing an original take on methodological reflection, largely through analogy with the study and practice of civil engineering, the text is written with wit and as such, it provides an entertaining read. Tulumello succeeds in provoking the reader to notice some major differences in how generalization is performed and justified in quantitative and qualitative social research, and how quality control operates through methodological caution, reflection and transparency. In so doing, he also touches on the question of methodological monism and pluralism in social sciences. In Tulumello's view, the proponents of quantitative methods tend to adopt a monist stance where quantitative analyses and theory building are proposed as a model for all social scientific work. Those working with qualitative approaches, again, largely agonize with uncertainty that ensues from methodological pluralism (see, e.g., Sheppard \& Plummer 2007; Rosenman et al. 2019).

The paper's perhaps greatest merit is the way it manages to bring two very different worlds of social research under the same rubric, and to discuss their differences in relation to each other instead of simply focusing on the strengths and weaknesses of one of them. Tulumello's polemical style succeeds in engaging and provoking the reader, but obviously also runs the risk of producing two methodological caricatures, one quantitative and one qualitative. The risk is further increased when ideal-typical notions of quantitative and qualitative methodology are employed in discussing their different modes of generalization, methodological transparency and scientific attitude (e.g. Poon 2005; Scott 2010). To do so is an understandable writing strategy in a polemical text, but I believe that the argument could be strengthened by including more reflection about the "gray area" between these opposite ends.

What I mean is taking explicit notice of the following kinds of possible counter-arguments. First, not all quantitative social research operates with sophisticated statistical methods and causal models as 
the mode of theory building - there is a lot of scholarship that employs quantitative data in a rather straightforward manner to illustrate or evidence conceptual points in much the same way that qualitative researchers do their analytical and theoretical work. Second, some qualitative researchers, too, make subjective choices concerning their conceptual, philosophical and ontological starting points "upstream", as Tulumello (2019) puts it, thus pushing their subjectivism out of sight in a way that has implications on the generalizability of their findings. Third, it seems obvious that some researchers using quantitative methods also employ subjective judgement "downstream", when interpreting their findings. Finally, not all qualitative researchers work with case study, and this has implications on how they frame (or leave aside) the question of generalizability. These are examples of the objections that readers familiar with less categorical variants of social research may have for the paper's argument.

Along these lines we could also ask, whether the idea of theory in qualitative and qualitative research is similar enough to merit comparison in terms of generalizability - could it rather be, as Sayer (1982) proposed already in the early 1980s, that we are comparing apples and oranges, so that the whole notion of generalization is set up and argued for differently, and with dissimilar aims as a mode of knowledge production? Should this be the case, it would be useful to discuss the issue to help cement the paper's point (excuse the pun). There is no doubt Tulumello (2019) is well aware of how the grey area between qualitative and quantitative extremes complicates the argument he proposes. This is indicated by his use of terms such as "quantitative/positivist" that adds some precision as to who he actually aims to refer to in the context of quantitative social research. He also makes a note of the rise of mixed methods approaches as a methodological strategy, which is why I believe Tulumello could well incorporate some of this reflection to his argument.

There is one final minor point that I laid a critical eye on. In discussing safety factors used in engineering, Tulumello characterizes social reality metaphorically as concrete. While this makes sense in the context of his argument, and is in alignment with the adopted style of writing, I would add a sentence that explicitly notes that this is a (deliberately) mechanistic metaphor that in itself could be criticized as reductionistic. These observations and remarks notwithstanding, Tulumello's essay has a particular merit. I hope the essay, and the comments that each in their own way expand on the original argument, increase our awareness of the importance of methodological transparency, caution, and reflection as part of social research quality control.

\section{Acknowledgements}

I wish to thank Fennia editors Kirsi Pauliina Kallio and James Riding for the possibility to engage in a stimulating conversation with Simone Tulumello on his inspiring essay.

\section{References}

Poon, J. P. (2005) Quantitative methods: not positively positivist. Progress in Human Geography 29(6) 766-772. https://doi.org/10.1191/0309132505ph583pr

Rosenman, E., Loomis, J. \& Kay, K. (2019) Diversity, representation, and the limits of engaged pluralism in (economic) geography. Progress in Human Geography [online Feb 27 2019] https://doi. org/10.1177/0309132519833453

Sayer, A. (1982) Explanation in economic geography: abstraction versus generalization. Progress in Geography 6(1) 68-88. https://doi.org/10.1177/030913258200600103

Scott, J. (2010) Quantitative methods and gender inequalities. International Journal of Social Research Methodology 13(3) 223-236. https://doi.org/10.1080/13645579.2010.482258

Sheppard, E. \& Plummer, P. (2007) Toward engaged pluralism in geographical debate. Environment and Planning A 39(11) 2545-2548. https://doi.org/10.1068/a40205

Tulumello, S. (2019) Generalization, epistemology and concrete: what can social sciences learn from the common sense of engineers. Fennia 197(1) 121-131. https://doi.org/10.11143/fennia.77626 